\title{
The Impact of Technological Innovation on Economic Growth: Evidence from China
}

\author{
Xiaowei Wang ${ }^{1, *}{ }^{*}{ }^{*}$ Lingwen $\mathrm{Xu}^{2, \dagger}$
}

\author{
${ }^{1}$ The University of Queensland \\ ${ }^{2}$ Renmin University of China \\ *Corresponding author. Email: xiaowei.wang1@uq.net.au \\ These authors contributed equally.
}

\begin{abstract}
The development of technological innovation has a significant impact on economic growth. Based on China's data from 1990 to 2019, we study the impact of technological innovation on China's economic growth. To solve this problem, this paper adopts theoretical mechanism analysis and empirical model research. The theoretical analysis results show that the progress of technology will make a country's economy develop continuously. By building the OLS model and WLS model, we find that when the government's financial expenditure on science and technology innovation increases, it will greatly improve economic growth. This shows that a country's economic growth needs the promotion of technology and the strong support of the government, and financial support has the most significant effect on economic growth.
\end{abstract}

\section{Keywords: Technological innovation, Economic growth, Regression Model}

\section{INTRODUCTION}

\subsection{Research Background and Motivation}

In 2021, WIPO IP Facts and Figures 2020, released by the World Intellectual Property Organization, shows that China is still the largest source country of international patent applications after 2019 [1]. The number of patent applications increased by $16.1 \%$ year on year, ranking first in the world with 68720. The growth of patent applications in China has exceeded the growth of GDP. Five of the top 10 companies with the largest number of applications in the world are all from China. In terms of field, computer technology accounts for the largest proportion of patent applications in the world. Meanwhile, the results of Nature Index 2020 annual tables show that China's high-quality scientific research output in the field of natural science ranks second in the world. Since 2015, scientific research output has increased by $63.5 \%$, which is the fastestgrowing country [2]. We care about technological innovation because it includes a series of production technologies used to design, manufacture, package, and deliver goods and services. Therefore, technology is the application of selected parts of the knowledge base in production activities. Within the enterprise, the combination of technology and other inputs determines the enterprise's production capacity [3]. Solow's model tells us that the sustained long-term economic growth mainly comes from technological progress because technological innovation increases the stock of knowledge available for production. China's scientific and technological innovation has made such great progress in the short term because the government's preferential tax policies continue to stimulate scientific and technological innovation, which has produced sustained effects. According to the data released by the State Taxation Administration of the People's Republic of China in 2021, during the 13th Five Year Plan period, China's cumulative tax reduction for encouraging scientific and technological innovation reached RMB 2.54 trillion [4]. This is equivalent to one-third of the total scale of tax reduction and fee reduction (more than RMB 7.6 trillion) during the 13th Five Year Plan period. It is enough to show that China attaches great importance to scientific and technological innovation.

The top beneficiary industries are the manufacturing industry and the high-tech service industry through the preferential tax policies. According to the data, manufacturing, information transmission, information technology services, scientific research, and technology services account for nearly $90 \%$ of the total tax reduction. The integrated circuit and software industry will enjoy more than RMB100 billion of tax reduction since 2019. 
In fact, in recent years, China's entire economy has been undergoing a gradual transformation. The new economic growth point is the industries and fields that China's tax reduction and fee reduction focus on. For example, the growth rate of investment and added value in high-end manufacturing and information technology industries in recent years is far higher than that of the economy as a whole and industries above scale. On the other hand, due to the continuous increase of $\mathrm{R} \& \mathrm{D}$ expense deduction, enterprises' R \& D investment and innovation vitality are effectively stimulated. China's R \& D investment has increased from RMB1.42 trillion in 2015 to RMB 2.44 trillion in 2020. It has become the second-largest R \& D investment country in the world. The above shows that scientific and technological innovation is the driving force of social and economic growth.

\subsection{Literature Review}

Lucas emphasized the role of knowledge as production input in his pioneering work on endogenous growth theory [5]. In the model, technological progress and industrial innovation drive long-term growth. Hasan et al. expanded this research direction by demonstrating that the quantity and quality of innovation are important to promote economic growth [6]. In addition, they investigated whether the impact of innovation on economic growth depends largely on the economic structure and development stage of different countries. They try to meet this demand by building transnational samples and solve this problem with the help of a global patent database. Based on OLS results, they found that countries with higher levels of patent activity tend to have higher growth rates. Chernyshev believes that productivity growth, especially technology growth, is extremely important in economic growth [7]. He tried to help us understand the state of innovation and technology-related phenomena. He thinks that innovation and technological growth factors come from the competition between innovative enterprises and the business cycle and from the transmission channel from technological growth to economic growth - the existence of production interdependence between enterprises in an economy. He regards the production linkage between industries as the amplification factor of the productivity growth within enterprises, enlarges and guides it to the whole economy level, and determines the link structure to strengthen the sector growth to the greatest extent. Chernyshev uses a company-level dataset of $\mathrm{R} \& \mathrm{D}$ information to study a broad version of the framework with economies of scale [7]. Through the empirical verification of the best structure of inter-departmental linkages by the prediction framework, we get the endogenous structure of inter-departmental linkages. Different from other literatures, our research object is only based on China's national conditions and data. Explain the impact of scientific and technological progress on economic development in developing countries.

China is in an important period of economic structure transformation. It is a good and typical example to show us the extent of the impact of technological development on the economy. We use the relevant data of the China statistical yearbook from 1990 to 2019 to verify our conjecture [8]. How much impact does the development of scientific and technological innovation have on economic growth in developing countries? How much strength should the government's fiscal policy support related industries. This paper will analyze the data, discuss the results and reasons based on the data analysis, and finally conclude the relationship between economic growth and technological innovation.

The research framework of this paper is as follows: the first part is the introduction, the second part is the data analysis and model construction, the third part is the estimation result analysis of the model, and the last part is the conclusion.

\section{METHODOLOGY}

\subsection{Research on the theoretical mechanism}

In today's international context of economic globalization, the economic competition of various countries or regions is becoming increasingly fierce. Science and technology's progress is considered the real driving force to promote sustained economic growth. At the same time, investment in science and technology is one of the core factors affecting the development of science and technology. The increase of the sum of social wealth and welfare is mostly simplified as the increase of a country's GDP. There are two ways of economic growth: one is to increase the input of production factors, the other is to improve the efficiency of production factors. The essence of the former's transformation is to give full play to the positive role of technology and knowledge in economic growth. Romer's new economic growth theory (R\&D model) endogenizes technological innovation in the model, thus forms the new economic growth theory based on neoclassical growth theory. It points out that technological progress is the source of economic growth and the result of the endogenous accumulation of knowledge. Technological progress depends on the labor, capital, and social knowledge stock of the R \&D department. So far, the decisive role of technological innovation and progress in economic growth has been fully affirmed and accepted by most people.

According to the new growth theory, $\mathrm{R} \& \mathrm{D}$ is an important factor of economic growth because R\&D can improve production technology and produce important external effects among enterprises. R\&D drives economic growth by promoting knowledge accumulation 
and technological innovation, which is the essential and decisive factor determining the quality of economic growth. The R\&D resources include labor, capital, material, and information resources. R\&D human resources mainly refer to the personnel of $R \& D$ activities. To compare countries or regions, they are generally converted into the full-time equivalent of R\&D personnel in statistics. Financial resources mainly refer to $R \& D$ funds and their proportion to GDP, including government funds and loans. At the same time, there are also scientific and technological achievements, which direct reflection of $R \& D$ investment results.

This paper argues three main factors to measure $R \& D$ investment and scientific innovation development: capital, human resources, and total scientific and technological achievements.

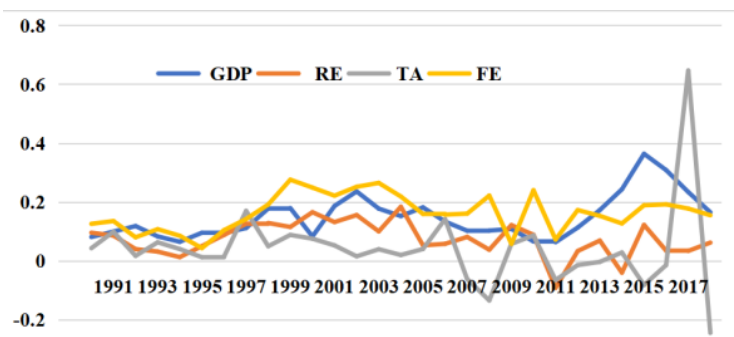

Figure 1. The Growth rate line plot

As can be seen from Figure 1, from 1990 to 2019, with the increase of China's GDP growth rate, the growth rate of fiscal expenditure on science and technology also shows an upward trend, while the growth rate of R\&D personnel's full-time equivalent is generally stable. It shows a downward trend in the later period. The total growth rate of scientific and technological achievements fluctuates greatly, and the overall trend is similar to the GDP growth rate. Therefore, we believe that these three factors have a certain role in promoting economic growth, and the degree of influence of each factor is worth studying and thinking about.

\subsection{Description of Data Indicators}

To study the impact of scientific and technological innovation on China's economic growth, this paper selects four indicators: GDP, totally scientific and technological achievements, fiscal expenditure on science and technology, and the full-time equivalent of $\mathrm{R} \& \mathrm{D}$ personnel. GDP is the core index of national economic accounting, which can well measure a country or region's economic growth and development level. The total amount of scientific and technological achievements refers to the number of scientific and technological achievements registered, including applied technology achievements, basic theory achievements, and soft science research achievements, which can directly reflect the achievements of scientific and technological development and the degree of innovation. Financial expenditure on science and technology refers to the government's expenditure and relevant departments supporting scientific and technological activities. Generally speaking, it refers to the scientific research expenditure arranged in the national budget. Improving a country's scientific and technological development level is closely related to the scale of scientific and technological investment, and it is the investment in scientific and technological innovation property. The full-time equivalent of R\&D personnel is a common international index used to compare scientific and technological manpower input, reflecting the output level and efficiency of R\&D activities.

\subsection{Data Source and Preprocessing}

The data source of this paper is the national statistical yearbook of 2000-2020 in the National Bureau of Statistics of China, and the time range of sample data is 1990-2019. Since the original data differs greatly on the scale, to ensure the accuracy of the estimated results, the variables are treated as logarithmic transformations. The new variables after processing are $\ln$ GDP, $\operatorname{lnFE}, \operatorname{lnTA}$, In RE. Thereinto, the FE variable refers to the financial expenditure on science and technology. The TA variable refers to the total amount of scientific and technological achievements. RE variable refers to the full-time equivalent of R \& D personnel.

\subsection{Descriptive Analysis of Data}

This paper calculates the eigenvalues of variables after logarithmic processing to further describe the data, and the results are shown in Table 1.

Table 1. Statistic Characteristic Value of variables

\begin{tabular}{c|c|c|c|c}
\hline Variable & $\ln$ GDP & $\ln$ FE & $\ln$ TA & $\operatorname{lnRE}$ \\
\hline Mean & 12.1 & 7.21 & 10.5 & 5.03 \\
\hline Max & 13.8 & 9.28 & 11.1 & 6.17 \\
\hline Min & 9.85 & 4.94 & 9.92 & 9.92 \\
\hline Standard Deviation & 1.18 & 1.4 & 0.31 & 0.7 \\
\hline Skewness & -0.21 & -0.03 & 0.46 & 0.27 \\
\hline Kurtosis & -1.19 & -1.49 & -0.83 & -1.59 \\
\hline
\end{tabular}




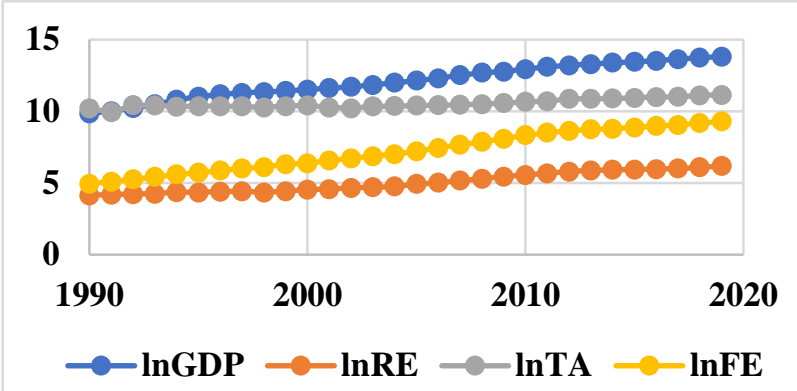

Figure 2. The Logarithmic index line plot

As shown in Figure 1 and Table 1, the four indicators show a steady upward trend with the increase of years. In terms of skewness, lnGDP and lnFE show a left-skewed distribution, while $\operatorname{lnTA}$ and $\operatorname{lnRE}$ show a right-skewed distribution. In terms of kurtosis, the distribution of the four indicators is flat compared with the normal distribution. The absolute value is larger, indicating that the distribution's steepness is different from the normal distribution.

\subsection{Model Construction and Estimation Results}

A multiple regression model is constructed to empirically investigate the direction and extent of the impact of scientific and technological innovation on China's economic growth. The expression of the model is as follows.

$\ln G D P=\beta_{0}+\beta_{1} \ln F E+\beta_{2} \ln T A+\beta_{3} \ln R E+\mu_{t}$

lnGDP is the explanatory variable, reflecting economic growth. $\operatorname{lnFE}$ is the total amount of scientific and technological achievements, $\ln$ TA is the expenditure of Finance and technology, and ln RE is the full-time equivalent of $R \& D$ personnel, $\mu_{t}$ is a random error term. $\beta_{0}$ is a constant term, $\beta_{\mathrm{i}}(\mathrm{i}=1,2,3)$ represents the coefficient of each factor.

In this paper, the OLS-based regression and heteroscedasticity test are carried out, and the spreadlevel plot of fitting value and student residuals is drawn as follows.

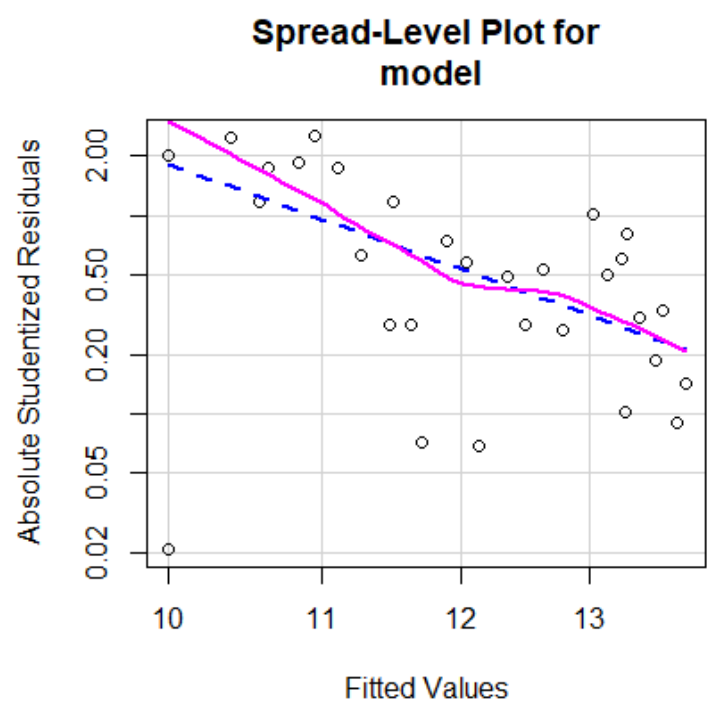

Figure 3. The spread-level plot

Since the fitting line does not maintain the basic level, heteroscedasticity is found, so the ordinary least squares (OLS) estimation result is no longer valid. Furthermore, the method proposed by White (1980) was used to test whether there was heteroscedasticity.

$$
\tilde{\mu}^{2}=\alpha_{0}+\sum \alpha_{i} X_{i}+\varepsilon
$$

$\widetilde{\mu}^{2}$ is the square of the residual of the original equation obtained from equation (1). The LM statistic is constructed according to Koenker's (1981) method

$$
n \times R^{2} \sim \chi_{k}^{2}
$$

Among them, $\mathrm{n}$ is the number of samples, $\mathrm{R}^{2}$ is the goodness of fit of the regression model (1). If the $\chi^{2}$ value is greater than the critical value under the given significance level, the original hypothesis of the same variance is rejected, indicating that the original equation has heteroscedasticity.

After testing, the LM statistic value is 17.234, p-value equal 0.0006325 , so the original hypothesis is rejected, and the original equation has heteroscedasticity. The $\mathrm{R}^{2}$ of the original equation is 0.83 , and the standard error is large.

This paper proposes the weighted least squares (WLS) method to solve the problem of heteroscedasticity. The idea is to give different weights to the residuals of the observed values of each sample, so that the random error term of the regression model has the same variance. The weighted model is as follows:

$$
\frac{\ln G D P}{\sqrt{h_{i}}}=\frac{\beta_{0}}{\sqrt{h_{i}}}+\beta_{1} \frac{\ln F E}{\sqrt{h_{i}}}+\beta_{2} \frac{\ln T A}{\sqrt{h_{i}}}+\beta_{3} \frac{\ln R E}{\sqrt{h_{i}}}+\frac{\mu_{t}}{\sqrt{h_{i}}}
$$

In this paper, we use the square of the residual to regress with the explanatory variable to get the fitting value $\widehat{g}_{i}$

$\hat{g}_{i}=\ln \left(u_{t}^{2}\right)=\alpha_{0}+\delta_{1} \ln F E+\delta_{2} \ln T A+\delta_{3} \ln R E$ 
So the weight is:

$$
\hat{h}_{i}=\exp \left(\hat{g}_{i}\right)
$$

Weighted least squares (WLS) can avoid the problem of heteroscedasticity of cross-sectional data, and the estimation results are unbiased, consistent, and effective. The estimated results are as follows:

Table2. Results of multiple regression model

\begin{tabular}{|c|c|c|c|}
\hline Variable & $\operatorname{lnTA}$ & $\operatorname{lnFE}$ & $\operatorname{lnRE}$ \\
\hline Coefficients & $0.4557^{*}$ & $1.2716^{* * * *}$ & $-1.0542^{\text {**** }}$ \\
\hline Standard error & 0.1682 & 0.0822 & 0.2002 \\
\hline $\mathrm{t}$ value & 2.71 & 15.47 & -5.27 \\
\hline Adjusted $\mathrm{R}^{2}$ & 0.994 & & \\
\hline $\mathrm{R}^{2}$ & 0.994 & & \\
\hline Constant & 3.426 & & \\
\hline
\end{tabular}

The final multiple regression model is as follow:

$$
\begin{gathered}
\ln G D P=3.426+0.4557 \ln F E+1.2716 \ln T A \\
-1.0542 \ln R E \quad(15) \\
t \text { value } \quad(2.52) \quad(15.47) \quad(2.71) \\
R^{2}=0.994 \quad F=1490
\end{gathered}
$$

\section{RESULT DISCUSSION}

From the regression model results, in the case of other variables unchanged in the model, the total amount of scientific and technological achievements increased by $1 \%$. The average economic growth increased by $45.57 \%$. When the fiscal expenditure on science and technology increased by $1 \%$, the average economic growth was $127 \%$. In terms of the significance of the parameters, the effects of R \& D personnel full-time equivalent (variable $\operatorname{lnRE}$ ), financial expenditure (variable $\operatorname{lnFE}$ ), and scientific and technological achievements (variable $\operatorname{lnTA}$ ) on economic growth (variable lnGDP) pass the parameter significance test at the 5\% significance level. It can be seen that the increase of scientific and technological achievements and financial investment will promote economic growth. Scientific and technological achievements have a strong pulling effect on economic growth, which is consistent with the view that science and technology are the primary productive force, and science and technology promote the economy. It is worth noting that when the $\mathrm{R} \& \mathrm{D}$ full-time equivalent input increases, it will lead to the slowdown of economic growth. It can be considered that under the condition of fixed scientific and technological achievements and financial investment in science and technology, appropriately reducing human resource investment is conducive to economic growth, reducing the cost investment in the process of scientific and technological innovation, to promote economic growth. From the significance of the model, the adjustable $\mathrm{R}$ square value of the model is 0.994 , which indicates that the goodness of fit of the model is high, and the value of F statistic is 1490 , the P-value is 0.00001 , It shows that the model is significant and further verifies the rationality of the model.

\section{CONCLUSION}

With the continuous growth of China's economy, we find that the Chinese government is also vigorously encouraging scientific and technological innovation in recent years. From the tax reduction of fiscal policy to the increasing investment in $R \& D$, the extent to which scientific and technological innovation can promote economic growth is the theme we want to study. Based on the China Statistical Yearbook data from 1990 to 2019 , this paper analyzes what factors have the greatest impact on economic growth in the field of scientific and technological innovation. In the meantime, we also get that to what extent will technological innovation stimulate economic growth.

Firstly, this paper analyzes the theoretical mechanism of scientific and technological innovation development and economic growth. GDP is chosen to describe economic growth. Choose $R \& D$ personnel full-time equivalent, government expenditure, and scientific and technological achievements as the main indicators to explain scientific and technological innovation development. We use the OLS model and WLS model to do empirical research on the above variables. Through the results of empirical research, we find that the support of fiscal policy has the greatest impact on the development of technology. When the fiscal expenditure increases by $1 \%$, the average economic growth will be as high as $127 \%$. On the contrary, when the full-time equivalent investment of $R \& D$ personnel increases, the economic growth will slow down. Finally, we conclude that under the same conditions of scientific and technological achievements and financial investment in science and technology, we should appropriately reduce 
the investment in human resources, which will be conducive to economic growth. On the other hand, the support of fiscal policy for science and technology will promote rapid economic growth to a large extent. Our research results once again verify that technological innovation has a positive effect on economic growth. At the same time, to a certain extent, it also answers the question raised at the beginning of the article: the strong support of fiscal policy for scientific and technological innovation will greatly promote economic growth.

In the long term, the promotion of economic development by technological progress has been a hot topic of concern to economists and governments. The conclusion of this paper is helpful for a government to make appropriate economic policies to promote economic growth by supporting technology. Solow Model and New Economic Growth Model tell us that only technological progress can promote economic growth in the long run. But we want to study the specific factors that affect scientific and technological innovation and the extent to which they can promote economic growth. This is also different from the usual literature. Through empirical analysis, we conclude that large-scale fiscal expenditure policy plays a very important role in promoting the development of science and technology and the economy. However, we need to further study what kind of financial policies should be made by governments under the nation's own conditions and whether these policies will bring about negative effects.

\section{REFERENCES}

[1] The WIPO IP Portal. (2021). WIPO IP Facts and Figures 2020.

[2] Nature Index. (2020). 2020 tables.

[3] Greenhalgh, C., \& Rogers, M. (2010). Innovation, intellectual property and economic growth. Princeton, N.J.: Princeton University Press.

[4] State Taxation Administration of The People's Republic of China. (2021)

[5] Lucas, Robert E. (1988). On the mechanics of economic development. Journal of Monetary Economics, 22(1), 3-42.

[6] Hasan, Iftekhar, \& Tucci, Christopher L. (2010). The innovation-economic growth nexus: Global evidence. Research Policy, 39(10), 1264-1276.

[7] Chernyshev, N. (2018). On the factors of innovation and economic growth (Order No. 27734985). Available from ProQuest Dissertations \& Theses Global. (2322004627).

[8] National Bureau of Statistics of China. (2021). 2020 China statistical yearbook. 